DOI:10.24193/tras.2017.0002

Published First Online: 2017/02/10

\title{
CO-GOVERNING SMART CITIES \\ THROUGH LIVING LABS. \\ TOP EVIDENCES FROM EU*
}

\author{
Francesco BIFULCO \\ Marco TREGUA \\ Cristina C. AMITRANO
}

\section{Francesco BIFULCO}

Associate professor, PhD, Department

of Economics, Management, Institutions,

University of Naples Federico II, Naples, Italy

Tel.: 0039-081-675.091

E-mail: francesco.bifulco@unina.it

\section{Marco TREGUA}

Research Fellow, PhD, Department

of Economics, Management, Institutions,

University of Naples Federico II, Naples, Italy

Tel.: 0039-081-675.070

E-mail:marco.tregua@unina.it

terized by smart cities projects, especially those implementing Living Labs initiatives as real-life settings to develop services innovation and enhance engagement of all urban stakeholders.

A research on the three top smart cities in Europe - i.e. Amsterdam, Barcelona and Helsin$\mathrm{ki}-$ is proposed through a content analysis with NVivo on the official documents issued by the project partners (2012-2015) to investigate their Living Lab initiatives.

The results show the increasing usefulness of Living Labs for the development of more inclusive smart cities projects in which public and private actors, and people, collaborate in innovation processes and governance for the co-creation of new services, underlining the importance of the open and ecosystem-oriented approach for smart cities.

Keywords: Smart city, Living Labs, governance, services innovation, multi-stakeholder.

Cristina C. AMITRANO (corresponding author)

Department of Economics, Management, Institutions, University of Naples Federico II, Naples, Italy

Tel.: 0039-081-675.091

E-mail: cristinacaterina.amitrano@unina.it

* Acknowledgments: This work has been supported by the project OR.C.HE.S.T.R.A. (Organizational of Cultural Heritage for Smart Tourism and Real-time Accessibility) in the Italian National Operative Programme 2007-13.

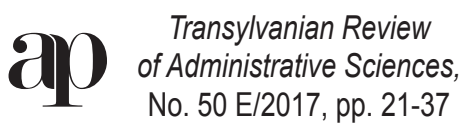




\section{Introduction}

European Commission is encouraging the development of smart cities since 2011, through funding and partnerships; at the end of 2015, smart cities have been defined as one of the priorities in the funding scheme of Horizon2020.

The attention paid by European Union (EU) is witnessed even by the growing number of smart cities projects; this phenomenon is related to the increasing urbanization and the subsequent demand for innovation in everyday activities that can be fulfilled with the development of enabling technologies - included in the paradigm of 'Internet of Things' - allowing people to participate in real-life contexts for a better quality of life.

Our focus is on the involvement of stakeholders through user-driven innovation (Almirall and Wareham, 2008), since stakeholders play a variety of roles in the smartization process; the choice of one or more types of innovative initiatives concerns different so-called drivers, namely economy, environment, mobility, governance, people, and living (Giffinger et al., 2007). Drivers are conceived as areas of interventions where improvements lead a city to become a smart city.

To sum up, smart cities aim at solving critical issues within urban areas (Lee, Hancock and Hu Lee, 2013), such as public services unavailability or shortages, traffic, over-development, environmental shortcomings, and other forms of inequality, all through ICT-based technology that is connected up as an urban infrastructure.

The role of technologies has been widely recognized but also criticized when overexploited (Haque et al., 2013), and ICT has even been accused of decreasing the role of people, their needs and resources (Klimovský, Pinterič and Šaparnienė, 2016). In order to avoid these issues, city managers have to identify and develop new forms of participation for all stakeholders in smart cities (Nam and Pardo, 2011), namely people, private sector actors, universities and research centers, institutions and organizations. In this way, all of the issues concerning the different drivers can be focused with the right balance between technological and human features.

The main field for the integration of ICT and stakeholders is governance, drawing on 'molecular democracy' (Kacser and Burns, 1979) and taking place thanks to the involvement of stakeholders in governance processes (Sandor, 2012). Recently, the 'Policy Making 2.0' emerged as 'a set of methodologies and technological solutions aimed at enabling better, timely and participative policy-making' (Koussouris et al., 2015).

The concept of governance was framed even in public networks and a similar approach has recently been applied to smart cities, as 'smart governance'; this latter is considered as highly relevant because stakeholders are engaged in the decision making process and outcomes are achieved through leverage on both technology and human factors (Johnston and Hansen, 2011). Different stakeholders have to be considered and smart governance is thought as a driver of smart cities by Giffinger et al. (2007) as 'related to participation in decision-making processes, transparency of governance systems, availability of public services and quality of political strategies'. 
So, governance in smart cities can be thought as the set of principles to guide activities with respect to the issues that emerge from the relationships among public administrations and internal and external stakeholders, with a focus on the collaboration of citizens through participation and engagement.

To achieve these results, one of the latest evolutions within smart cities projects is the implementation of Living Labs (LLs); they promote the idea achievable through a smart city (Hielkema and Hongisto, 2013) and represent a new way to bring together city managers and all the urban actors, to create an innovation-oriented environment. The complex sets of actors built around LLs are strictly connected to governance issues, as highlighted in literature (Komninos, Pallot and Schaffers, 2013); in details, LLs consist of real-life settings in which every actor plays a fundamental role, especially citizens (Nam and Pardo, 2011), through their activities towards the co-creation of new services, products, and societal infrastructures thanks to user-driven innovation.

To sum up, this paper reviews the literature on participative approaches to innovation and city governance to highlight both the gaps encouraging further research on these topics and where our contribution lays. After describing our methodology, findings and discussions are provided together with limitations and further research avenues.

\section{Literature review}

\subsection{User-driven innovation in public services}

Many scholars have theorized how innovation is changing - particularly in public services (Fuglsang, 2008) - due to new technologies, resource integration dynamics, and relationships among different actors and institutions (Chesbrough, 2011). Scholars consider stakeholders' participation so necessary to be promoted by a governance characterized by openness, involvement, and the inclusion of socio-cultural contexts (Almirall and Wareham, 2008).

Open innovation is related to the multi-stakeholder analysis in different fields, and ICTs are needed to favor interactions, even in innovating public services (Lindberg-Repo and Dube, 2015), as occurs in collaborative innovation (Chesbrough, 2011) and in so-called ecosystem innovation (Adner and Kapoor, 2010).

The improvements expected through openness, regarding the involvement of actors had already been discussed (von Hippel, 2005) and similar thoughts were expressed when complementing openness with realism and empowerment (Bergvall-Kåreborn and Stahlbröst, 2009), namely with the consideration of needs and opportunities that emerge from the daily contexts, and the chances offered by increasing motivations of actors shaping an innovation ecosystem. Motivating people with different aims and backgrounds is complex, and managers have to administer an intricate set of relationships both in private businesses context and in public services (Fuglsang, 2008).

Recently innovation in public services has become increasingly relevant (Lindberg-Repo and Dube, 2015), due to the chances offered by new technologies (Carrillo 
et al., 2014). This new perspective is even depending on citizens' support and their increasing needs for services integration (Magnusson, 2003).

Due to the elements shaping the innovation processes, a multi-stakeholder perspective (Bifulco, Tregua and Amitrano, 2014) is well suited to cities; thoroughly, scholars have highlighted the relevance of a wide set of stakeholders (Nam and Pardo, 2011), even if citizens keep the most important role.

\subsection{Living labs and public services}

Scholars called for research relating services and innovation (Wuenderlich et al., 2015), to highlight the contribution offered by consumers to improve value propositions. Moreover, research efforts are needed to provide new insights about the multiple-user local communities of future-'sensored' cities (Glasmeier and Christopherson, 2015).

When looking at cities, the service innovation approach is more open as city governance favors multi-actor collaboration. In detail, city managers and their business partners are orchestrators of the complex innovation systems emerging in cities (Yigitcanlar, 2008), as it occurs in LLs. In fact, a LL is 'both an innovation milieu and an innovation approach' (Bergvall-Kåreborn and Ståhlbröst, 2009, p. 356). The approach to LL is useful to overcome firms' boundaries (Cosgrave, Arbuthnot and Tryfonas, 2013) as it concerns innovation from contributions offered by stakeholders, in line with open innovation (Chesbrough, 2011) and aiming at reducing the costs in acting with open innovation communities.

The starting phase of a multi-stakeholder innovation process aims at combining the suitable quantity and quality of resources, leading to merge resource integration with innovation, namely the so-called 'intensification of innovation' (Dodgson et al., 2002). To achieve this goal, supra-national institutions, such as the EU, have recently begun to offer technical support to the creation of LLs. In this way, unfruitful projects can be avoided, as the resources to be leveraged are available from the start, as in cross-border innovation (Schaffers and Turkama, 2012).

In the past, it was common to derive evidence of the above-described approach from private-based contexts, while nowadays similar approaches are also found in cities (Schaffers and Turkama, 2012; Cosgrave, Arbuthnot and Tryfonas, 2013). However, scholars highlight how hard it is to achieve positive outcomes due to the huge differences in culture, the hindrances represented by laws, the complexity in managing systems such as cities, and money shortage (Bergvall-Kåreborn and Stahlbröst, 2009).

The manageability is even harder when cities and LLs start to collaborate, as methodologies and strategies need to be adapted to the context and the complexity deriving from the wide set of stakeholders; anyway, LLs are considered as a way to favor a participatory governance (Veeckman and van der Graaf, 2015).

Parallel to this, there are also advantages in combining different urban contexts, as best practices emerge and catalyze the improvements in some areas (Hewitt, 1999), even in areas wider than a city (Ben Letaifa, 2015). 
LLs are one of the ways in which cities are trying to attain innovative services provision for citizens and other local actors. Additionally, the different contributions offered by each stakeholder (Bergvall-Kåreborn and Ståhlbröst, 2009) cannot be suitably described using a network logic, as the boundaries of a city and the multitude of active stakeholders are more similar to an ecosystem (Veeckman and van der Graaf, 2015).

LLs are contexts in which multiple actors collaborate to achieve common aims through resource integration, new technologies, and continuous relationships (Schaffers and Turkama, 2012; Bifulco, Tregua and Amitrano, 2014) both inside and outside the boundaries of the LL itself (Bergvall-Kåreborn and Ståhlbröst, 2009). Hence, LLs mirror the activities shaping an innovation ecosystem, and ICT allows data collection (Cosgrave, Arbuthnot and Tryfonas, 2013), generation of ideas, and the extension of the available knowledge (Tsigkas, 2013).

The relationships are fruitful and self-sustaining as the results are useful to acquire long-term resources for current actors and for the ones to be further involved (Hielkema and Hongisto, 2013). This approach highlights how flexible and blurred boundaries are, unlike in the past when multi-actor innovation took place only in temporary activities (Cosgrave, Arbuthnot and Tryfonas, 2013; Bifulco et al., 2016).

People engagement is the core of LLs creation (Almirall and Wareham, 2008), as local agencies, businesses, citizens, universities, research centers, and actors from other cities shape a LL (Rothaermal and Thursby, 2005), in which mutual cooperation aims to further both common and divergent goals.

The role of governance is crucial (Cosgrave, Arbuthnot and Tryfonas, 2013), since public-private partnerships are commonly used (Walravens, 2012), and entail a distinctive meaning from mixed partnerships (Argento et al., 2010) due to the wider range of stakeholders and citizens' involvement (Veeckman and van der Graaf, 2015). Moreover, governance should convey a common idea of smart city (Ben Letaifa, 2015) and act in an adaptive way to propose solutions suitable to the changing needs of all actors.

Both public and private actors cooperate in LLs, no matter cities' sizes or characteristics, because the common element for all cities is the merger among systems; the notion of system is helpful in linking LLs and cities as innovation ecosystems and in highlighting their relevance in furthering the deployment of smart projects, as underlined by both scholars (Hollands, 2008; Ben Letaifa, 2015) and institutions, like the EU.

LLs have been set up and labeled differently all around Europe, due to the contexts and the opportunities offered by the EU or the European Network of Living Labs (ENOLL). Official reports by EU on its projects have underlined the relevance of a combination of digital skills, innovation, creativity, and technologies to improve how services are conceived, offered, provided, and evaluated for continuous upgrading. Additionally, the self-production of new ideas, and the self-evaluation and support offered by all actors are means to overcome the hindrances represented by missing financial resources. 
The bigger the area, the higher the number of issues facing local governance; hence, as it is not easy to favor specific interventions and discard others, the main aim is the creation of a set of actors ready for different activities. When several actors take part in LLs, explorations of needs, problem-solving activities, and evaluations of interventions are made easier (Anthopoulos, 2015). To confirm the success of combining LLs and innovation ecosystem, we refer to the urban innovation ecosystems, as introduced by Komninos (2011) and confirmed by the EU (European Investment Bank, 2012). This concept suggests considering cities as innovation contexts; furthermore, technology acts as the glue among actors and services that enables the collection of knowledge, ideas, and data, and to elaborate data to further improve service provisions.

\section{Emerging gaps and research aim}

Services innovation is a pivotal issue in smart cities as the multiplicity of needs and actors, the involvement of different agents and the key role played by the management system are shaping scholars' debate (Marsal-Llacuna, Colomer-Llinàs and Meléndez-Frigola, 2015). Innovation processes have recently been analyzed through the concept of service ecosystem (Akaka and Vargo, 2015), connecting the ties among actors, the resources to be used and generated, and the technologies to be implemented.

The gap emerging from the literature review is a clear focus on the elements highlighting how services are being innovated in smart cities through LLs; moreover scholars are paying attention to how city governance promotes collaborations (Koussouris et al., 2015; Veeckman and van der Graaf, 2015) to achieve common aims from the so-called smartization process.

Research calls on the above-depicted topics have been issued by scholars (Almirall and Wareham, 2008), with particular reference to LLs (Levén and Holmström, 2012). Specifically, Almirall and Wareham (2008) underlined the effectiveness of LLs in supporting and involving users, in line with our research aim to analyze user-driven innovation; anyway, the same authors highlighted how open innovation can guide the processes in LLs.

Recently, McPhee et al., (2016) stressed the call for research about LLs to grasp meanings about their key features and because of the role they will play in the coming decade.

Due to the reasons above, our aim is to underline the role of governance choices in cities (Lee and Lee, 2014) characterized by smart initiatives, when LLs are chosen as both a methodology and a tool (Bergvall-Kåreborn and Ståhlbröst, 2009; Almirall, Lee and Wareham, 2012) to develop services innovation and enhance citizens' engagement in urban life (Veeckman and van der Graaf, 2015).

Governance has been highlighted in literature as a crucial issue with respect to governance models and activities (Johnston and Hansen, 2011), smart governance (Anttiroiko, Valkama and Bailey, 2013), and the impact of governance on sustainability (Bifulco et al., 2016), livability (Loorbach, 2007) and services performance (Lee, Hancock and Hu Lee, 2013). 
However, the perspective above and the interplay between LLs and governance in cities aiming at becoming smart have not yet been considered, but could be used to underline the choices made by city governance and how the engagement of people is crucial (Coe, Paquet and Roy, 2001).

Moreover, LLs represent a suitable unit of analysis to understand how city governance sets up collaborations among actors. Finally, the ecosystem approach mirrors the characteristics of a city as highlighted through the literature review (Veeckman and van der Graaf, 2015), due to the variety of actors performing activities and to the blurred boundaries.

\section{Methodology}

\subsection{Research questions}

The research perspective we considered most suitable is a qualitative approach, due to the novelty of the topic (Lee, 1999) and to the limited number of empirical contexts. In detail, cities already being considered as smart cities are few, due to the complexity and the novelty of smartization. Additionally, as we want to grasp meanings about and from contexts projected and shaped to reach smartization, the analysis is based on the contents available from documents and reports; in line with methodological suggestions (Tesch, 1990) a content analysis is the most fitting method to acquire information from raw data and improve our knowledge.

The research questions are related to the approaches used by smart cities' main actors to manage the relationships between the actors involved in these initiatives, and how the implementation of LLs could help city governance in the co-creation of value, especially thanks to citizens' participation.

To sum up, the first research question looks for highlighting the key elements shaping innovation through LLs in cities. The aim of this focus is to provide evidence about both elements and actors shaping the innovation process in the LLs related to smart cities.

Then, the second research question aims to describe the actions carried on by city governance to lever on both actors and elements shaping the innovation processes in LLs towards the expected goals.

\subsection{Data collection}

Three cases (Amsterdam, Barcelona, Helsinki) were selected for their high ranking in the European Parliament's report - last release in 2014 - on top-performing smart cities in Europe (European Parliament, 2014) and the development of at least four smart projects.

This process enabled study of the three smart cities and their LL initiatives through a content analysis with NVivo (Silver and Lewins, 2014) using the official websites of - and the several documents and reports prepared by - the institutions. The software was chosen because of its reliability compared to the others (Krippendorff, 2013) and its easiness of use for some tools (Silver and Lewins, 2014). 
We considered official documents and reports issued for smart projects or initiatives in the three cities by actors directly involved, like local agencies, ICT firms, other companies, or supra-national organizations such as the EU or its agencies.

We chose to look for documents using a web search engine (i.e. Google), and selected the top 10 results for each of the three cities by looking at the typology of the file (to prevent critical issues during the analysis) and the language used in the documents (to ensure comparability between the documents and the queries).

Data selection was made jointly by all three authors (Silver and Lewins, 2014) to decrease subjectivity (Krippendorff, 2013), and to give more reliability to both dataset and results. When looking at the first evidences emerging through the web search engine, we discarded any reports that arose twice, and then selected the first 10 items for each of the three cases.

The choice of 10 reports depended even on the willingness to grasp meanings only from reliable documents (Silver and Lewins, 2014), namely the ones with a complete set of information. Then the whole dataset was controlled via the options offered by NVivo. As a consequence, thirty documents were considered and the time span of their year of issue ranged from 2012 to 2015. Finally, a test was performed on the two separate halves of the dataset to test the validity, deriving from the correspondence between the comparisons of the evidences, in line with Weber's suggestions (1990).

\subsection{Data analysis}

We read the documents before analyzing them in NVivo, so the findings will be presented first as an overview and then with the outcomes arising from the software. More specifically, we performed an analysis on two levels (Bazeley, 2003), since we first looked at the general outcomes from word frequency by considering the words emerged as relevant, namely the ones directly related to the issues of smart cities; additionally, we removed the words considered useless for the analysis, as proper nouns, articles, and so on.

This process was performed by all authors separately to improve reliability and decrease subjectivity (Krippendorff, 2013); then the outcomes have been compared one to another to achieve a final list to launch the rest of the analysis. This first step helped us in depicting the key elements in the innovation process carried on through LLs.

The list gave us the opportunity to examine the linkages among the most cited topics, instead of just considering them as stand-alone elements. Thus, this part of the investigation led to a focus on the most relevant topics in line with our research questions, namely LLs and the actions performed by city governance. To perform the analysis on the linkages, we grouped the topics as 'stemmed words', that is, words with a common root or a similar meaning.

All authors cooperated in confirming the groups automatically created by the software. Any unsatisfactory combinations were discarded and the categories reset before launching again the analysis and deriving meanings. The linkages considered are all based on a Jaccard's proximity index (ranging on a scale from 0 to +1 ) equal or superior to +0.9 (Iodice D'Enza and Palumbo, 2002). 


\section{Findings}

\subsection{A brief overview of the three cities}

Amsterdam: Before starting the Amsterdam Smart City (ASC) project in 2009, Amsterdam Living Lab (ALL) had already been launched in 2008 to test new products for several firms. The ALL played a crucial role in the city's smart development as it led to collaborations both inside and outside the city. Widespread collaborations also took place among inhabitants, local businesses, research centers and local agencies regarding environmental issues; additionally, Amsterdam was involved in ENOLL to benefit from resource integration with actors dealing with smart projects in Europe.

Barcelona: The 22@Barcelona district created a LL to support business innovation and to enable better usage of public spaces. The positive outcomes achieved led the city managers to promote new initiatives built around public services, transport, ecology, and ICTs. The role of universities was fundamental in teaching how to manage relationships in LLs and in promoting a culture of open innovation based on citizens and making the city an open laboratory. The key results are related to creativity, innovation, culture, and knowledge; these elements emerged thanks to scholars, local organizations, city managers, and the local community.

Helsinki: The Finnish Living Lab in Helsinki was set up before the two labs above, and unlike them it directly focused on urban innovation, rather than on new products. Public organizations, local agencies, and citizens acted together to attain innovative community services through digital instruments. Moreover, user-driven innovation was particularly promoted and only after achieving the first outcomes related to public services, firms were allowed to test innovation they deployed internally. The feedback emerging from users' experience for both public services and firms' innovation formed a best practice applied all over Europe to acquire information for both evaluations and improvements.

\subsection{Evidence from the qualitative analysis through NVivo}

The results emerged through NVivo are presented in Table 1; each word represents a category of similar topics in terms of meanings. The meanings grasped thanks to the focus on each of these words is useful to answer to the first research question, viz. to give evidence to elements and actors shaping the innovation process in the three LLs analyzed.

Apart from obvious evidences (e.g., city, smart), the word frequency analysis performed on 30 official reports provides interesting insights into the key issues. First, among the services to be offered in a city there is a huge prominence of 'energy' as the issue attracting most attention.

Another interesting result is 'development'; due to the general meaning of this word, we read again reports and noticed that services are most commonly linked to development. We confirmed this by performing a proximity analysis, namely a query to highlight the words most commonly surrounding a topic within the documents; 
Table 1: Top results from word frequency analysis

\begin{tabular}{|c|c|c|c|c|c|}
\hline Word & Count & $\begin{array}{c}\text { Weighted Percentage } \\
(\%)\end{array}$ & Word & Count & $\begin{array}{c}\text { Weighted Percentage } \\
(\%)\end{array}$ \\
\hline City & 3245 & 2.43 & using & 805 & 0.60 \\
\hline energy & 1522 & 1.14 & Amsterdam & 689 & 0.51 \\
\hline smart & 1369 & 1.02 & Technology & 662 & 0.49 \\
\hline development & 1117 & 0.83 & public & 648 & 0.48 \\
\hline region & 909 & 0.68 & data & 643 & 0.48 \\
\hline systems & 904 & 0.68 & Informed & 598 & 0.45 \\
\hline Helsinki & 888 & 0.66 & businesses & 548 & 0.41 \\
\hline projects & 869 & 0.65 & opens & 484 & 0.36 \\
\hline innovators & 853 & 0.64 & solutions & 480 & 0.36 \\
\hline services & 813 & 0.61 & builds & 480 & 0.36 \\
\hline
\end{tabular}

Source: Authors' elaboration through NVivo

in this way it was possible to better contextualize a topic through its meaning by looking at the sentences embedding it. Labels such as 'services', 'new services', and 'innovative services' are frequently used together with 'development', which reveals that the cities are reporting on the attention paid to the improvement of services and the proposal of new ones. Other interesting topics linked to 'development' are 'local areas', 'economic', and 'territorial'.

By analyzing the word frequency even the word 'system' emerged; this result allows us to compare the theoretical perspective with the practical approach adopted by the actors issuing the reports. Literature review provided evidence on the linkage between LLs and innovation ecosystems, while the organizations are using 'system' to describe the contexts in which smart projects are deployed.

'Innovators' represents another relevant category from the word frequency analysis useful in recalling user-driven innovation, and we looked at the whole word group to understand the meanings of both innovation activities and actors. The root 'innovat-' groups words useful to describe the approach ('innovative', 'innovativeness'), the actors ('innovators'), and the activities ('innovation', 'innovating', etc.).

Finally, the word frequency analysis yielded another main result, namely 'services', although this concept has already been mentioned when debating about 'development'. We found a number of linkages with the previous result, namely the word grouped under the tag 'innovators', thus we understood that services designed and provided in smart cities need to be innovative to better satisfy the needs emerging from the actors shaping LLs.

The second step of our analysis was to investigate the linkages among the most relevant topics emerging from the word frequency analysis to answer to the second research question and to show how city governance is acting to carry on the smart city projects. We again analyzed only the most significant results, based on Jaccard's proximity index equal or superior to +0.9 (Fig. 1). 


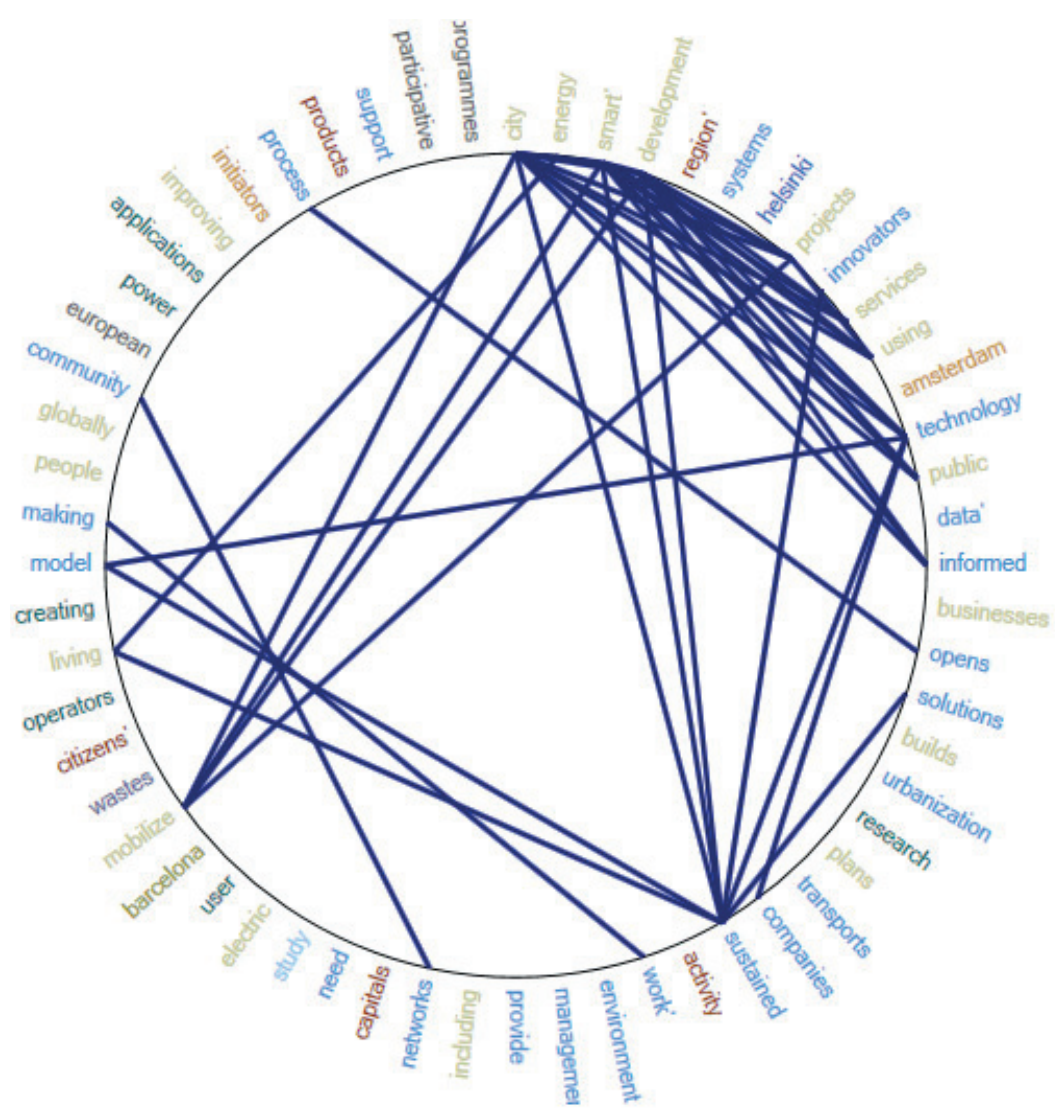

Figure 1: Linkages among the most frequent topics

Source: Authors' elaboration through NVivo (Linkages based on Jaccard's proximity index $\geq+0.9$ )

The ties among the topics are easily understandable and in some cases expected, such as between 'smart' and 'city', 'smart' and 'region', 'city' and 'region', 'city' and 'services', and 'smart' and 'services'.

The first tie considered is between 'development' and 'services', as this is useful to confirm our previous findings; that is, that services innovation is seen as a priority in smart city projects, and that it is a crucial aim when LLs promote improvement in quality of life. Another interesting result related to 'development' is the linkage to 'technology', as this did not emerge from the previous step; thus, it is useful both to investigate our dataset in depth and to describe how 'technology' and 'development' are mutually connected, as technology favors development, but the development of technology supports smart city projects and the activities in LLs.

Another linkage is shaped by 'innovators' and 'sustained'; by analyzing the words shaping these groups, we can state that innovators sustain the innovation process in LLs, and innovation as a process is sustainable (or feasible) only if the actors are engaged in supporting through resource integration. 
Similarly, the linkage between 'sustained' and 'development' concerns developments to be achieved only if properly sustained by actors carrying out the innovation process through LLs. A similar linkage is given by 'sustained' and 'solution', as problem-solving activities have to be made sustainable, or feasible, through the contribution of the different actors.

Furthermore, the tie between 'sustained' and 'model' has a wider perspective, since the approach to feasibility still remains as stated before, but when discussing the model proposed in LLs for smart cities, the perspective is wider because the model addresses sustainability more generally, and not only concerning resources.

Finally, the ecosystem approach is highlighted through the linkage between 'opens' and 'process', as these categories represent the way innovation processes should be - and are - set up in LLs. Thus, openness represents a key feature in shaping and performing innovation processes for smart cities.

\section{Discussion and implications}

LLs in Amsterdam, Barcelona, and Helsinki led us to enlarge the concept of smart cities as complex systems developed by public and private organizations to the ecosystem-oriented approach introduced by management literature (Adner and Kapoor, 2010). Thus, we provide evidence of the increasing importance of the actors involved in smart cities projects, especially when LLs are both a methodology and tool for actors' collaboration, resource integration, and development of innovative technologies (Almirall, Lee and Wareham, 2012).

The results show the increasing importance of LLs in the innovation process based on the support offered by all actors in the theoretical perspective known as user-driven innovation. This approach is suitable for the development of more inclusive smart cities projects in which all actors collaborate (Walravens, 2012) for the diffusion of innovation in cities.

This wider perspective, which focused on the participation of different actors in smart cities (Rothaermal and Thursby, 2005) - emerging as the wide category of 'innovators' -, is related to the openness, as boundaries of LLs are permeable and many contributions can be made from external actors (Cosgrave, Arbuthnot and Tryfonas, 2013).

The innovation process in public services (Carrillo et al., 2014; Lindberg-Repo and Dube, 2015) made possible through LLs should be as open as possible as it emerged from the analysis because these choices bring together different perspectives and support user-driven innovation (Magnusson, 2003) wherever users are (Bergvall-Kåreborn and Ståhlbröst, 2009) thanks to the use of technologies, especially the integrated platforms.

The development of new services is crucial in smart city projects and it is a need in improving the answers to citizen needs; this consideration is a contribution to the call for research by Wuenderlich et al. (2015). New services are proposed through technology, as one of the focal features of a LL, since it levers the resources collected through 
a 'molecular democracy' (Kacser and Burns, 1979) towards the 'intensification of innovation' (Dodgson et al., 2002)

In detail, LLs support a more democratic and inclusive approach in smart cities and represent a motivation for city governance to drive these initiatives through actors engagement (Coe, Paquet and Roy, 2001), which represents the main reason for their success, even if aims can diverge (Walravens, 2012).

The proactive participation of actors (Bergvall-Kåreborn and Ståhlbröst, 2009), especially citizens, the co-creation of innovative services, the attempt to ensure sustainability, and the use and upgrade of technologies represent useful areas for the integration of the service ecosystems (Veeckman and van der Graaf, 2015) with governance processes. The pivotal roles played by actors involved in innovation processes within cities emerge as strictly related to a delineation of the complementary processes of governance; moreover, thanks to the contribution of all actors, financial constraints can be overcome (Bergvall-Kåreborn and Stahlbröst, 2009).

In smart cities, innovation processes need to be integrated with governance processes that have to be shared, rather than top-down or bottom-up (Giffinger et al., 2007). Governance concerns all the activities that aim towards the sharing of power in decision making (Anttiroiko, Valkama and Bailey, 2013), to experience autonomy and independence thanks to a different perspective on power and democracy - all these aspects can be more easily reached through the development of real-life contexts for user-driven innovation, namely LLs.

Governance should sustain innovation, namely act as both a connector and a collector of actors and resources. This approach requires citizens' involvement (Veeckman and van der Graaf, 2015) and a common idea of smart city (Ben Letaifa, 2015).

\section{Conclusions and research limitations}

To sum up, governance can be seen as linked to the activities in LLs, as people's involvement, engagement, and contributions are all supportive elements towards the expected results (Magnusson, 2003). Technology are means to allow people's contributions towards common aims in smart city projects (Carrillo et al., 2014) and to lever on knowledge combination (Tsigkas, 2013).

The relationships among technologies, practices, and features of the service ecosystem can be viewed through the lens of governance, as the contribution of new technologies has allowed the development of horizontal networks (Anttiroiko, Valkama and Bailey, 2013) between different stakeholders groups. These groups represent resources and knowledge integrators (Tsigkas, 2013) for value co-creation, as well as city governments, who conduct different projects - such as city web portals, online platforms and the so-called e-governance -, and open data that engage people and allow the co-creation of smart services.

Our results enlarge the above-delineated perspective, and reveal that LLs favor and enhance people's engagement in smart cities, and also within innovative governance processes (Bifulco et al., 2016). The decisional process is shared because it is 
based on a common path towards innovation, in line with the idea of problem-solving activities (Anthopoulos, 2015) in LLs.

To answer the call for further research made by Almirall and Wareham (2008), this research considered various elements to provide a better definition of what LLs can do to innovate ecosystems such as cities; we suggest that LLs should engage a suitable and wide set of actors and resources to enable the sustainability of smart city projects. This perspective is aligned with the 'Policy Making 2.0' (Koussouris et al., 2015) and based on the community and the networks of actors within a city. When recalling networks of actors, businesses' participation, role of community and sustainability, governance activities became co-governing activities as the participation shapes the decisions (Anttiroiko, Valkama and Bailey, 2013).

Sustainability has to be intended as a way to ensure feasibility; hence, when both private and public actors carry out smart city projects they need to fill the knowledge and resource gaps that act as hindrances when smart cities projects are deployed in a long-term perspective (Hielkema and Hongisto, 2013). The set of actors and resources to leverage towards such aims is not intended to be static, but needs continuous improvement due to the increasing complexity of city ecosystems.

A wider set of evidences from smart city projects and the LLs would have been useful in improving the evidences; parallel to this, a longitudinal approach would improve the reliability of the results by furthering research, even though data collected cover a time span from 2012 to 2015. Anyway, as long as upgrades of the smart city ranking will be available, new investigations are possible. Moreover, interviews with city managers and other actors contributing to services innovation in cities would be useful to complement and compare the outcomes, due to the role of key informants. Finally, it would be useful to enlarge the contest of analysis to a worldwide perspective.

\section{References:}

1. Adner, R. and Kapoor, R., 'Value Creation in Innovation Ecosystems: How the Structure of Technological Interdependence Affects Firm Performance in New Technology Generations', 2010, Strategic Management Journal, vol. 31, no. 3, pp. 306-333.

2. Akaka, M.A. and Vargo, S.L., 'Technology as An Operant Resource in Service (Eco) systems', 2014, Information Systems and e-Business Management, vol. 12, no. 3, pp. 367384 .

3. Almirall, E. and Wareham, J., 'Living Labs and Open Innovation: Roles and Applicability', 2008, The Electronic Journal for Virtual Organizations and Networks, vol. 10, no. 3 , pp. 21-46.

4. Almirall, E., Lee, M. and Wareham, J., 'Mapping Living Labs in the Landscape of Innovation Methodologies', 2012, Technology Innovation Management Review, vol. 2, no. 9, pp. 12-18.

5. Anthopoulos, L.G., 'Understanding the Smart City Domain: A Literature Review', in Rodríguez-Bolívar, M.P. (ed.), Transforming City Governments for Successful Smart Cities, Cham: Springer, 2015, pp. 9-21. 
6. Anttiroiko, A.V., Valkama, P. and Bailey, S.J., 'Smart Cities in the New Service Economy: Building Platforms for Smart Services', 2013, Artificial Intelligence E Society, vol. 29, no. 3, pp. 323-334.

7. Argento, D., Grossi, G., Tagesson, T. and Collin, S.O., 'The 'Externalisation' of Local Public Service Delivery: Experience in Italy and Sweden', 2010, International Journal of Public Policy, vol. 5, no. 1, pp. 41-56.

8. Bazeley, P., 'Computerised Data Analysis for Mixed Methods Research', in Tashakkori, A. and Teddlie, C. (eds.), Handbook of Mixed Methods in Social and Behavioral Research, Thousand Oaks: Sage Publications, 2003, pp. 385-422.

9. Ben Letaifa, S., 'How to Strategize Smart Cities: Revealing the SMART Model', 2015, Journal of Business Research, vol. 68, no. 7, pp. 1414-1419.

10. Bergvall-Kåreborn, B. and Ståhlbröst, A., 'Living Lab: An Open and Citizen-centric Approach for Innovation', 2009, International Journal of Innovation and Regional Development, vol. 1, no. 4, pp. 356-370.

11. Bifulco, F., Tregua, M. and Amitrano, C.C., 'Living Labs for Smart Innovation: A User-centric Approach', in Freund, L. and Cellary, W. (eds.), Advances in The Human Side of Service Engineering, AHFE Conference Edited Books, 2014, pp. 282-294.

12. Bifulco, F., Tregua, M., Amitrano, C.C. and D'Auria, A., 'ICT and Sustainability in Smart Cities Management', 2016, International Journal of Public Sector Management, vol. 29, no. 2, pp. 132-147.

13. Carrillo, F.J., Yigitcanlar, T., García, B. and Lönnqvist, A., Knowledge and the City: Concepts, Applications and Trends of Knowledge-based Urban Development, New York: Routledge, 2014.

14. Chesbrough, H., 'Bringing Open Innovation to Services', 2011, MIT Sloan Management Review, vol. 52, no. 2, pp. 85-90.

15. Coe, A., Paquet, G. and Roy, J., 'E-governance and Smart Communities a Social Learning Challenge', 2001, Social Science Computer Review, vol. 19, no. 1, pp. 80-93.

16. Cosgrave, E., Arbuthnot, K. and Tryfonas, T., 'Living Labs, Innovation Districts and Information Marketplaces: A System Approach for Smart Cities', 2013, Procedia Computer Science, vol. 16, pp. 668-677.

17. Dodgson, M., Gann, D.M., and Salter A.J., 2002, 'The Intensification of Innovation', International Journal of Innovation Management, vol. 6, no. 1, pp. 53-83.

18. European Investment Bank, 'JESSICA for Smart and Sustainable Cities', 2012, [Online] available at http://www.eib.org/attachments/documents/jessica_horizontal_study_ smart_and_sustainable_cities_en.pdf, accessed on March 15, 2016.

19. European Parliament, 'Mapping Smart Cities in EU', 2014, [Online] available at http:// www.europarl.europa.eu/RegData/etudes/etudes/join/2014/507480/IPOL-ITRE_ ET(2014)507480_EN.pdf, accessed on March 15, 2016.

20. Fuglsang, L., 'Capturing the Benefits of Open Innovation in Public Innovation: A Case Study', 2008, International Journal of Services Technology and Management, vol. 9, no. 3-4, pp. 234-248.

21. Giffinger, R., Fertner, C., Kramar, H., Kalasek, R., Pichler-Milanovic, N. and Meijers, E., 'Smart Cities-Ranking of European Medium-sized Cities', 2007, [Online] available at http://www.smart-cities.eu/download/smart_cities_final_report, accessed on March $15,2016$. 
22. Glasmeier, A. and Christopherson, S., 'Thinking about Smart Cities', 2015, Cambridge Journal of Regions, Economy and Society, vol. 8, no. 1, pp. 3-12.

23. Haque, M.M., Chin, H.C. and Debnath, A.K., 2013, 'Sustainable, Safe, Smart-Three Key Elements of Singapore's Evolving Transport Policies', Transport Policy, vol. 27, pp. 20-31.

24. Hewitt, W.T., 'Cities Working Together to Improve Urban Services in Developing Areas: The Toronto-Sao Paulo Example', 1999, Studies in Comparative International Development, vol. 34, no. 1, pp. 27-44.

25. Hielkema, H. and Hongisto, P., 'Developing the Helsinki Smart City: The Role of Competitions for Open Data Applications', 2013, Journal of the Knowledge Economy, vol. 4, no. 2, pp. 190-204.

26. Hollands, R.G., 'Will the Real Smart City Please Stand Up? Intelligent, Progressive or Entrepreneurial?', 2008, City, vol. 12, no. 3, pp. 303-320.

27. Iodice D'Enza, A. and Palumbo, F., 'Iterative Factor Clustering of Binary Data', 2012, Computational Statistics, vol. 28, no. 2, pp. 789-807.

28. Johnston, E.W. and Hansen, D.L., 'Design Lessons for Smart Governance Infrastructures', in Balutis, A.P, Buss, T.F. and Ink, D. (eds.), Transforming American Governance: Rebooting the Public Square, New York: ME Sharpe, 2011, pp. 197-212.

29. Kacser, H. and Burns, J.A., 'Molecular Democracy: Who Shares the Controls?', 1979, Biochemical Society Transactions, vol. 7, no. 5, pp. 1149-1160.

30. Klimovský, D., Pinterič, U. and Šaparnienè, D., 'Human Limitations To Introduction Of Smart Cities: Comparative Analysis From Two CEE Cities', 2016, Transylvanian Review of Administrative Sciences, no. 47E, pp. 80-96.

31. Komninos, N., 'What Makes Cities Smart?', SC Conference, Edinburgh June 30, 2011, [Online] available at http://www.urenio.org/wp-content/uploads/2008/11/Whatmakes-cities-smart-Edinburgh-30062011.pdf, accessed on March 15, 2016.

32. Komninos, N., Pallot, M. and Schaffers, H., 'Special Issue on Smart Cities and the Future Internet in Europe', 2013, Journal of the Knowledge Economy, vol. 4, no. 2, pp. 119-134.

33. Koussouris, S., Lampathaki, F., Misuraca, G., Kokkinakos, P. and Askounis, D., 'The Decalogue of Policy Making 2.0: Results from Analysis of Case Studies on the Impact of ICT for Governance and Policy Modelling', in Boughzala, I., Janssen, M. and Assar, S. (eds.), Case Studies in e-Government 2.0, New York: Springer, 2015, pp. 163-182.

34. Krippendorff, K., Content Analysis: An Introduction to Its Methodology, $3^{\text {rd }}$ edition, Thousand Oaks: Sage Publications, 2013.

35. Lee, T.W., Using Qualitative Methods in Organizational Research, London: Sage, 1999.

36. Lee, J. and Lee, H., 'Developing and Validating a Citizen-centric Typology for Smart City Services', 2014, Government Information Quarterly, vol. 31, suppl. 1, pp. S93-S105.

37. Lee, J.H., Hancock, M.G. and Hu, M.C., 'Towards an Effective Framework for Building Smart Cities: Lessons from Seoul and San Francisco', 2013, Technological Forecasting and Social Change, vol. 89, pp. 80-99.

38. Levén, P. and Holmström, J., 'Regional IT Innovation: A Living Lab Approach', 2012, International Journal of Innovation and Regional Development, vol. 4, no. 2, pp. 129-143.

39. Lindberg-Repo, K. and Dube, A., 'Customer Value Dimensions in e-Healthcare Services: Lessons from Finland', 2015, International Journal of E-Services and Mobile Applications, vol. 7, no. 4, pp. 17-29. 
40. Loorbach, D., 'Governance for Sustainability', 2007, Sustainability: Science, Policy $\mathcal{E}$ Practice, vol. 3, no. 2, pp. 1-4.

41. Magnusson, P.R., 'Benefits of Involving Users in Service Innovation', 2003, European Journal of Innovation Management, vol. 6, no. 4, pp. 228-238.

42. Marsal-Llacuna, M.L., Colomer-Llinàs, J. and Meléndez-Frigola, J., 'Lessons in Urban Monitoring Taken from Sustainable and Livable Cities to Better Address the Smart Cities Initiative', 2015, Technological Forecasting and Social Change, vol. 90, part B, pp. 611-622.

43. McPhee, P., Leminen, S., Schuurman, D., Westerlund, M. and Huizingh, E., 'Editorial: Living Labs and User Innovation', 2016, Technology Innovation Management Review, vol. 6, no. 1, pp. 3-6.

44. Nam, T. and Pardo, T.A., 'Smart City as Urban Innovation: Focusing on Management, Policy, and Context', in Estevez, E. and Janssen, M. (eds.), Proceedings of the 5th International Conference on Theory and Practice of Electronic Governance, New York: ACM, 2011, pp. 185-194.

45. Sandor, S.D., 'ICT and Public Administration Reforms', 2012, Transylvanian Review of Administrative Sciences, no. 36 E, pp. 155-164.

46. Schaffers, H. and Turkama, P., 'Living Labs for Cross-Border Systemic Innovation', 2012, Technology Innovation Management Review, September 2012, pp. 25-30.

47. Silver, C. and Lewins, A., Using Software in Qualitative Research: A Step-by-step Guide, $2^{\text {nd }}$ edition, London: Sage Publications, 2014.

48. Tesch, R., Qualitative Research: Analysis Types and Software Tools, London: Routledge, 1990.

49. Tsigkas, A.C., The Lean Enterprise. From the Mass Economy to the Economy of One, Heidelberg: Springer, 2013.

50. von Hippel, E., Democratizing Innovation, Cambridge, MA: MIT Press, 2005.

51. Veeckman, C. and van der Graaf, S., 'The City as Living Laboratory: Empowering Citizens with the Citadel Toolkit', 2015, Technology Innovation Management Review, vol. 5, no. 3, pp. 6-17.

52. Walravens, N., 'Mobile Business and the Smart City: Developing a Business Model Framework to Include Public Design Parameters for Mobile City Services', 2012, Journal of Theoretical and Applied Electronic Commerce Research, vol. 7, no. 3, pp. 121-135.

53. Weber, R.P., Basic Content Analysis, Newburry Park, CA: Sage, 1990.

54. Wuenderlich, N.V., Heinonen, K., Ostrom, A.L., Patricio, L., Sousa, R., Voss, C. and Lemmink, J.G., 'Futurizing Smart Service: Implications for Service Researchers and Managers', 2015, Journal of Services Marketing, vol. 29, no. 6/7, pp. 442-447.

55. Yigitcanlar, T. Velibeyoglu, K. and Baum, S. (eds.), Knowledge-Based Urban Development: Planning and Applications in the Information Era, Hershey, PA: IGI Global, 2008. 